\title{
Test flattening in the larger foraminifer Heterostegina depressa: predicting bathymetry from axial sections
}

\author{
Wolfgang Eder, Johann Hohenegger, and Antonino Briguglio
}

\begin{abstract}
Previous attempts to quantify the test-flattening trend in Heterostegina depressa with water depth have been rather unsuccessful. Due to its broad depth distribution, $H$. depressa is a perfect model species to calibrate test flattening as a bathymetric signal for fossil assemblages. This might enable us to better reconstruct paleoenvironments of fossil communities of larger foraminifera or even provide clues to the degree of transport in allochthonous deposits. In this study, we used growth-independent functions to describe the change of test thickness throughout ontogeny. Four growth-invariant characters, deriving from these functions, clearly quantify a transition of individuals with thicker to thinner central parts along the water-depth gradient. This transition is probably controlled by light intensity, because the photosymbionts of $H$. depressa (diatoms) are most effective at low irradiation levels. Thus, specimens at shallower depths grow thicker to reduce light penetration, whereas specimens living deeper than the light optimum increase their surface by flattening to obtain better exposure to light.
\end{abstract}

Wolfgang Eder and Johann Hohenegger. Department of Palaeontology, University of Vienna, Althanstrasse 14, 1090 Vienna, Austria.E-mail: wolfgang.eder@univie.ac.at, johann.hohenegger@univie.ac.at

Antonino Briguglio. DI.S.T.A.V. - Dipartimento di Scienze della Terra, dell'Ambiente e della Vita Università degli Studi di Genova Corso Europa, 26 I - 16132 Genova, Italy. E-mail: antonino.briguglio@unige.it

Accepted: 29 July 2017

Published online: 24 January 2018

Data available from the Dryad Digital Repository: http:/ / doi.org/doi:10.5061/dryad.mm720

\section{Introduction}

Larger benthic foraminifera (LBF) are a nontaxonomic group of benthic protists unified by their symbiotic relationship with photosynthetic microalgae. They have developed multiple times throughout earth history from different smaller benthic forms. Due to their symbionts, they can reach larger test sizes but are restricted to the photic zone of tropical to warm-temperate shallow-marine environments. Their increasingly large test sizes led to a diversification in test morphology and a development of a complex inner structure. For instance, the family of LBF studied herein, the Nummulitidae, build a complex multilamellar calcitic test with a well-developed channel system to enhance mass transport within the test (Hallock 2000; BouDagher-Fadel 2008).

In the past decades, LBF have been highlighted as important biostratigraphic indicators (Cahuzac and Poignant 1997; Serra-Kiel et al. 1998). Additionally, nummulitids in particular have been distinguished as highly informative facies fossils (Hallock and Glenn 1986; Beavington-Penney and Racey 2004). These inferences on the ecology of fossil nummulitids were possible due to thorough actuopaleontological research on the intricate ecological constraints of larger benthic foraminiferal test morphology (Reiss and Hottinger 1984; Hallock et al. 1986, 1991; Hottinger 2000; Hohenegger 2009, 2011a; Prazeres et al. 2015; Eder et al. 2017a). Their shape and function is strongly influenced by two major factors: first, the intrinsic need to provide and shelter their symbionts, developing so-called microscopic greenhouses (sensu Hohenegger 2011b); and second, the need to adapt to physical factors of their immediate environment, mainly light attenuation and hydrodynamic energy (Hottinger 2000; Hohenegger 2004; Briguglio and Hohenegger 2009; Seddighi et al. 2015). The importance of the ecological adaptation of test thickness to water depth as a paleoecological indicator has been thoroughly studied (Haynes 1965; Hottinger 1977a; Hallock 1979, 1988; Hallock et al. 1991; Beavington-Penney and Racey 2004; Cosovic 
et al. 2004; Hohenegger 2004, 2009, 2011b), whereby the most commonly used indicator is the thickness/diameter $(T / D)$ ratio. Several authors, however, have reported the $\mathrm{T} / \mathrm{D}$ ratio's limited applicability as a water-depth indicator (Reiss and Hottinger 1984; Hallock and Glenn 1986; Renema 2005; Hohenegger 2011a). This is mainly because its significance is restricted to species whose flattening is obtained by thinning of the lamellae (Hallock et al. 1986).

The nummulitid Heterostegina depressa d'Orbigny, 1826 is the only extant representative of the heterosteginine subfamily; Planostegina and Planoperculina represent a parallel evolutionary lineage and should not be included (Banner and Hodgkinson 1991; Holzmann et al. 2003). Generally, its test coiling is characterized by an approximated logarithmic spiral and arched chambers that are subdivided into chamberlets by complete secondary septa (septula) (Hottinger 1977b; Hohenegger 2011b). It is a cosmopolitan species of tropical to warm-temperate, photic, shallow-marine environments and shows the broadest depth distribution within the extant nummulitids; it occurs from the uppermost subtidal down to around $100 \mathrm{~m}$ water depth (Banner and Hodgkinson 1991; Hohenegger 2004). This species hosts Thalassionema-type diatom symbionts, which clearly differ from the diatoms of all other extant nummulitids (Holzmann et al. 2006); their highest photosynthetic rates are achieved at an optimal photosynthetic active radiation around 100 to $150 \mu \mathrm{mol} \mathrm{m} \mathrm{m}^{-2} \mathrm{~s}^{-1}$ (Nobes et al. 2008). Thus, $H$. depressa reacts to suboptimal light conditions by test modification (flattening), which, however, weakens resistance against high water energy and entrainment (Reiss and Hottinger 1984; Hohenegger 2009).

In the present study, we use $H$. depressa to apply a new methodology to measure and model test thickness in nummulitids based on Hohenegger (2011a). This analysis demonstrates that the growth functions, introduced here, can be used to describe the ontogenetic change of thickness in $H$. depressa. Furthermore, growth-invariant characters deriving from these functions can be used to illustrate the continuous change in test shape with water depth. Finally, we discuss how the hydrodynamic regime, light intensity, and attenuation, as well as habitat properties, can influence these observed growth patterns. The resulting data will present the base for establishing a model for metric morphoclines using axial sections of Heterostegina depressa living in oligotrophic rimmed-shelf environments. This article aims to connect bathymetrically correlative environmental parameters (e.g., light intensity and sediment proportion) to test morphology, so fossil Heterostegina taxa can be better used as paleoenvironment indicators.

\section{Material and Methods}

We used 127 specimens of $H$. depressa from water depths of 5 to $90 \mathrm{~m}$ (coll. J.H.). All selected specimens were megalospheric tests and were collected offshore at Sesoko-Jima in two transects $\left(26^{\circ} 39^{\prime} 5.134^{\prime \prime} \mathrm{N}, 127^{\circ} 51^{\prime} 11.635^{\prime \prime} \mathrm{E}\right.$ and $26^{\circ} 39^{\prime} 38.776^{\prime \prime} \mathrm{N}, 127^{\circ} 51^{\prime} 56.280^{\prime \prime} \mathrm{E}$ ) in 1993 and 1996 (Fig. 1). Samples down to $40 \mathrm{~m}$ were collected by SCUBA, whereas deeper samples were dredged. Undisturbed distribution patterns were recorded by picking only living specimens from the sediments (for more information refer to Hohenegger et al. 1999). Sampling was done before the annual typhoon season to rule out down- or upslope transport of living specimens.

Axial sections were obtained by microcomputed tomography $(\mu \mathrm{CT})$ visualization, which is frequently used to observe, quantify, and model foraminiferal test morphology in a nondestructive way (Speijer et al. 2008; Briguglio and Hohenegger 2011; Hohenegger and Briguglio 2012; Briguglio et al. 2013; Ferrandez-Canadell et al. 2014; Eder et al. 2016). The images used in this study were taken with the high-energy scanner Skyscan 1173 at the University of Vienna (Department of Palaeontology). DataViewer, Version 1.4.4.0 was used to extract the axial sections from the three-dimensional data sets.

Statistical Analysis.-Two growth functions (sensu Hohenegger 2011a) describe the ontogenetic development in thickness of $H$. depressa and were used in this study. The mediolateral thickness $(M l T h)$ represents the test thickness at the radius center of the measured whorl, which can be used to approximate the test 


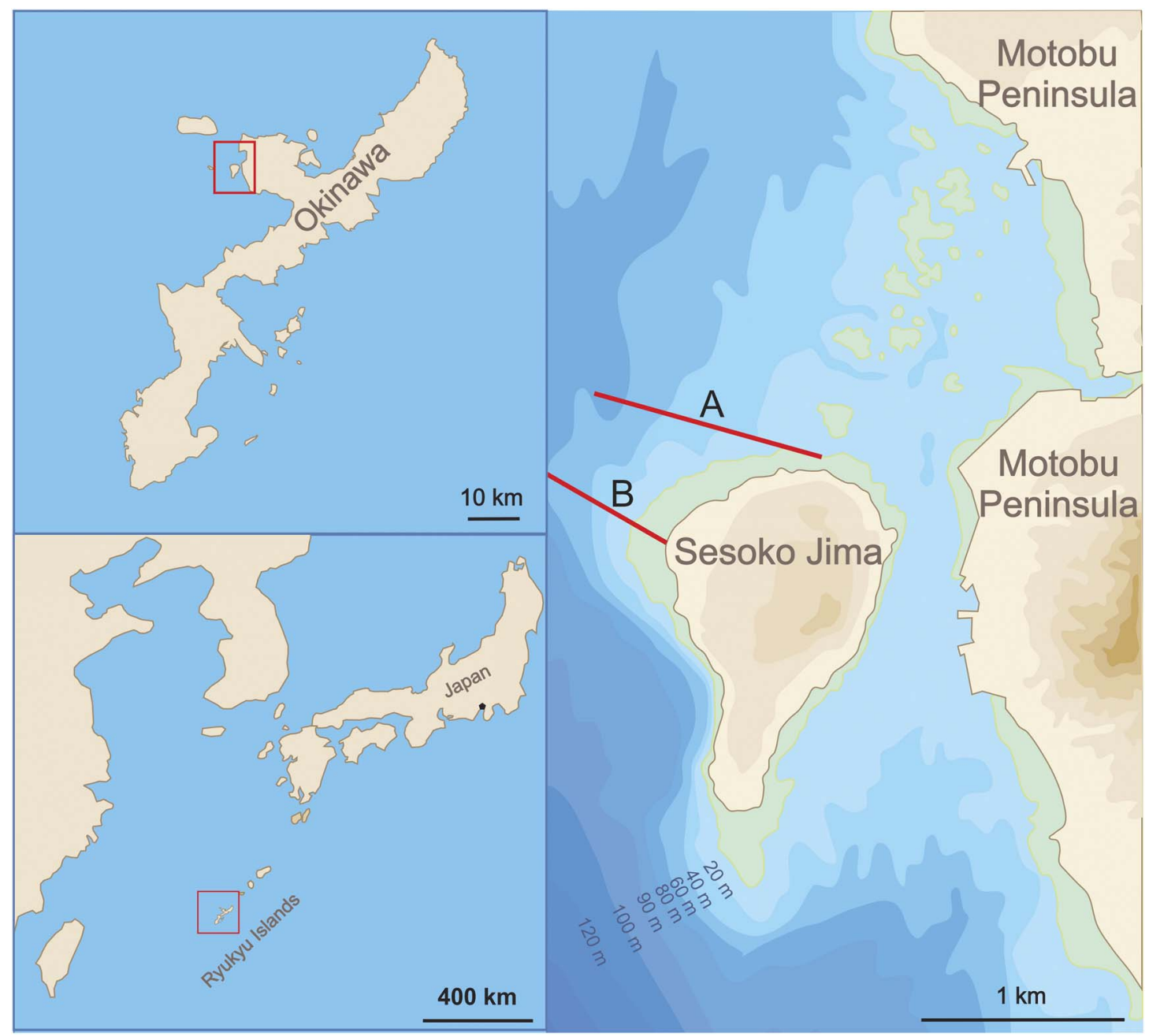

FIGURE 1. Illustration of the sampling area, Sesoko-Jima, Okinawa, Japan. The Northern and Southern transects as described by Hohenegger et al. (1999) are indicated as A and B, respectively.

shape in axial view. It relates to the mediolateral thickness of an ellipsis, since the whorls of planspiral foraminifera in axial section can best approximated by an ellipse. The change in mediolateral thickness during ontogeny can be shown by relating the mediolateral thickness with the corresponding marginal radius $M R$. We therefore measured MlTh at five locations on each shell's axial section (Fig. 2). These positions were chosen to represent the embryonic, juvenile, and adult spiral. For the initial test, the thickness at the radius center of the proloculus (embryonic) and the first whorl (juvenile) were measured. The mediolateral thickness of the last three half-whorls were measured for the adult spiral. For a detailed explanation of the mediolateral thickness, refer to Hohenegger (2011a: Fig. 1D).

Based on these measurements, the MlTh of the whole test was computed by,

$$
M l T h=b_{0}\left(M R+b_{3}\right)^{b_{1}} e^{b_{2}\left(M R+b_{3}\right)}
$$

which is a composite function consisting of a power and exponential function. The parameters $b_{0}$, the multiplicative constant, $b_{1}$, the allometric constant, $b_{2}$, the restriction rate, and $b_{3}$, an additive radius constant, were estimated by nonlinear regression using IBM-SPSS, Version 22. The constants $b_{0}$ and $b_{1}$ control the power function, and $b_{2}$ determines the decrease in the exponential function, while $b_{3}$ controls the position of the maximum. 


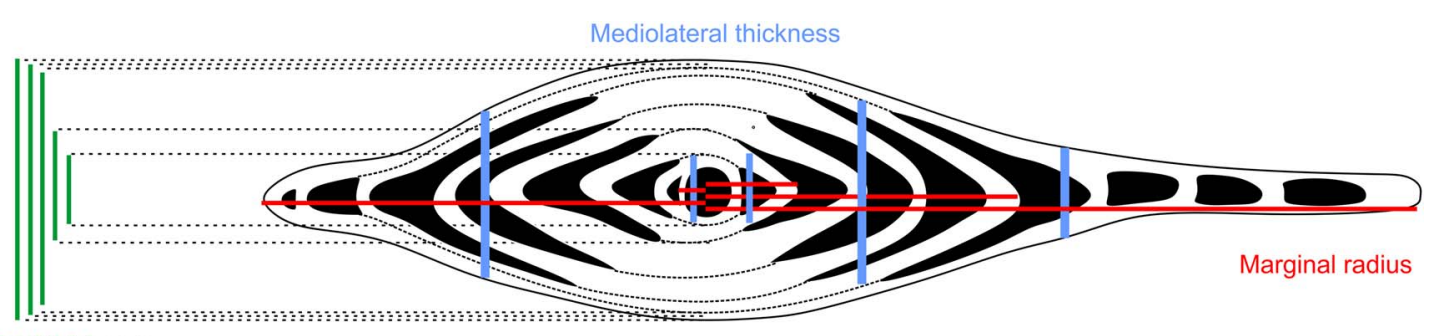

Total thickness

FIgURE 2. H. depressa in axial view. Measurements of mediolateral thickness $(M l T h)$ are indicated in blue; total thickness (Th) in green; and corresponding radii in red.

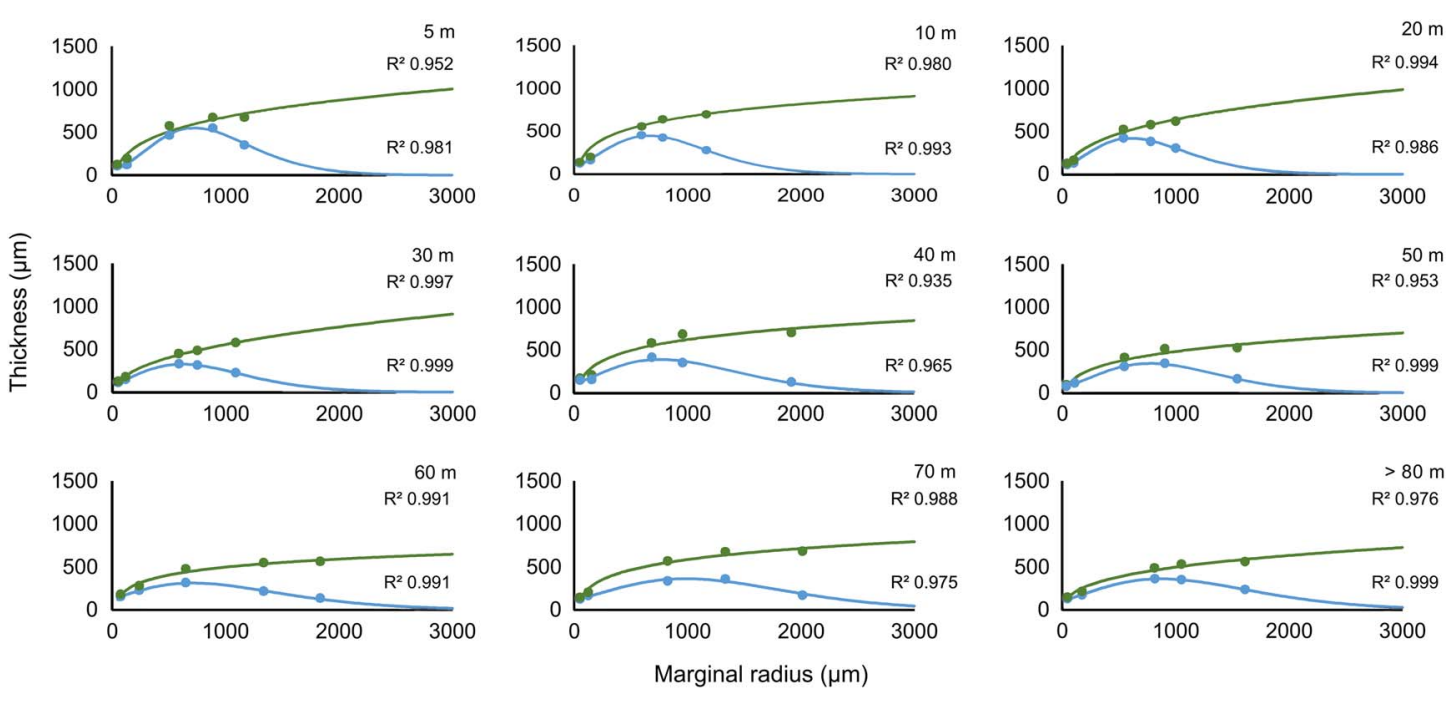

FIGURE 3. The two growth functions for a single specimen of $H$. depressa from each water-depth interval are shown. The mediolateral thickness is indicated in blue, with thickness in green. Filled dots represent the measurements depicted in Fig. 1. The corresponding functions of MlTh and Th are given along with their coefficient of determination $R^{2}$.

In addition, the thickness $(T h)$ at the test center was measured in axial sections at the same five positions mentioned earlier (Fig. 2). Its increase depends on the radius and can be approximated by a power function

$$
T h=a \cdot M R^{b}+c
$$

where $a$ is the multiplicative constant, $b$ the growth rate, and $c$ the offset from the equatorial plane (Eder et al. 2017b). This function describes how the thickness/diameter ratio changes during growth, thus discouraging the use of a fixed $T / D$ ratio for depth estimation in Heterostegina and in all LBF with similar growth geometry (Fig. 3). The diagrams display function lines for equations (1) and (2) for a single specimen from each water-depth interval. The schematic drawing (Fig. 4A) illustrates the progression of the growth functions in an axial section to demonstrate how the mediolateral and total thickness change with test size.

Based on these functions, the following growth-independent characters can describe flattening tendencies in $H$. depressa: the thickness ThMR3 is calculated at a $3 \mathrm{~mm}$ marginal radius by substituting $3 \mathrm{~mm}$ for $M R$ in equation (2). This parameter characterizes the same relationship as the $T / D$ ratio but allows comparison between individuals, because specimen size is fixed, thus becoming a growth-independent character. The template given in Appendix 3 in the Supplementary Material (doi:10.5061/dryad.mm720) can be used to calculate the given characters based on the function parameters of equations (1) and (2). 

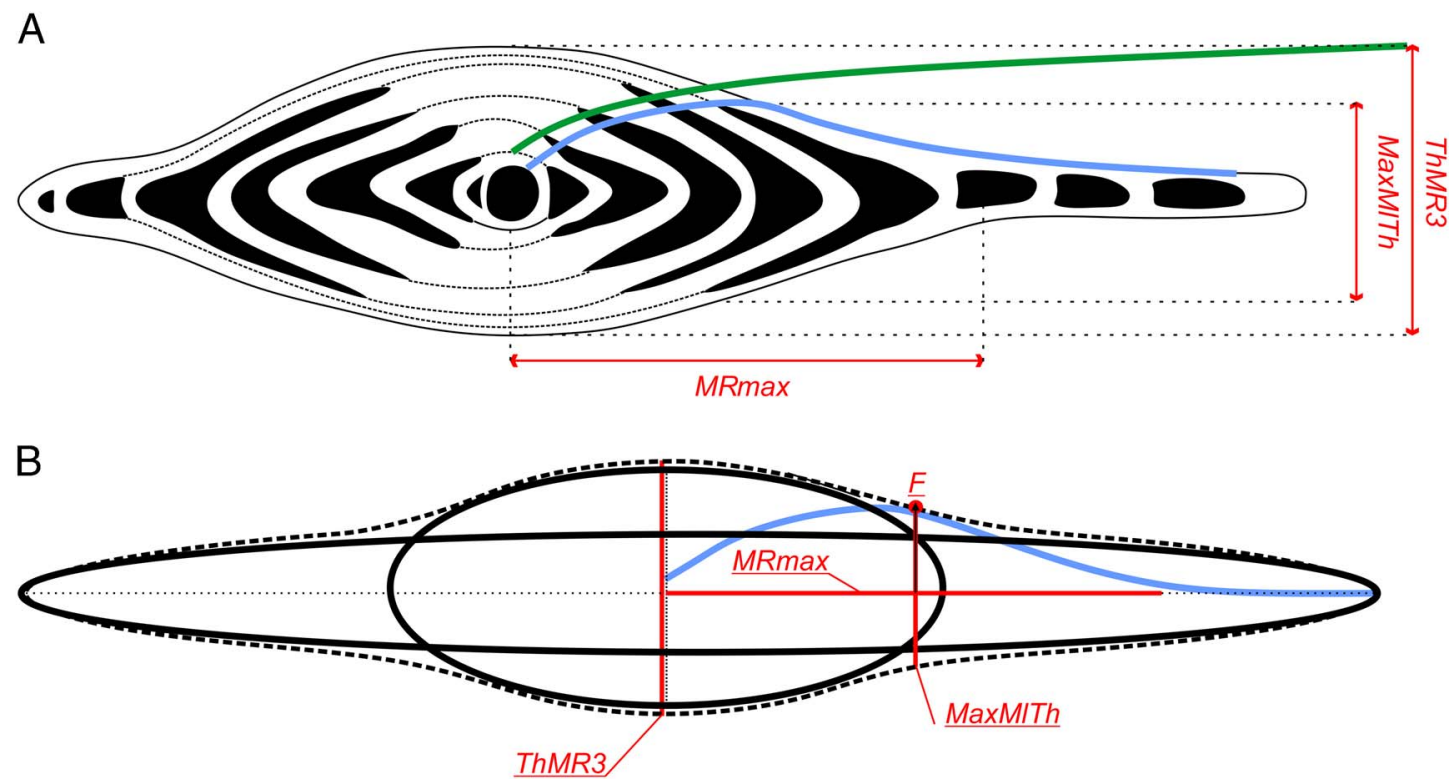

FIGURE 4. A, The growth function for mediolateral thickness (blue) and for thickness (green) plotted over an axial section. The unidimensional growth-invariant characters ThMR3, MRmax, and MaxMlTh are depicted in red. B, Schematic illustration of the axial shape of $H$. depressa, consisting of a combination of two different ellipses. The intersection point of MRmax and MaxMlTh projected onto the test surface indicates the onset point of test flattening. This is described by the ratio of MRmax to MaxMlTh, herein called F.

Another growth-independent character for evaluating flattening is the maximum mediolateral thickness (MaxMlTh), computed based on equation (1). This calculation, however, requires the radius at the point of maximal mediolateral thickness (MRmax). Its center is located at the inflection point of the function resulting from equation (1) (Fig. 4B), determining the position of the mediolateral thickness along the equatorial plane. To gain $M R \max$, the first derivative of equation (1),

$M l T h^{\prime}=b_{0}\left(b_{3} M R\right)^{b_{1}-1}\left(b_{2} M R+b_{2} b_{3}+b_{1}\right) e^{b_{2} M R+b_{2} b_{3}}$

must be set to zero. By inserting parameters $b_{1}$, $b_{2}$, and $b_{3}$, the marginal radius MRmax can then be computed using equation (4).

$$
M R \max =-\left(b_{2} b_{3}+b_{1}\right) / b_{3}
$$

Consequently, the maximal mediolateral thickness MaxMlTh can be calculated by fitting MRmax into equation (1).

In maturo-evolute species such as $H$. depressa, the test shape in axial section combines two shapes: an initial thick ellipse transferring into a final thin one (Fig. 4B). Thus, the intersection between the maximal mediolateral thickness MaxMlTh and its marginal radius MRmax describes the transfer point between these two different shapes and marks the onset of test flattening. The projection of this intersection point onto the test surface is best described by the ratio between MaxMlTh and MRmax (flattening ratio F; see Fig. 4B). The linear relationship between numerator and denominator running through the origin manifests a correct use of the ratio and was tested by Pearson's correlation coefficient.

The two growth functions and four derived growth-independent and growth-invariant characters (i.e., radius at the point of maximal mediolateral thickness MRmax, maximal mediolateral thickness MaxMlTh, thickness at $3 \mathrm{~mm}$ marginal radius $T h M R 3$, and the flattening ratio F) (see Fig. 4) were computed for all specimens of $H$. depressa at a $5 \mathrm{~m}$ depth, and from $10 \mathrm{~m}$ to $70 \mathrm{~m}$ in $10 \mathrm{~m}$ intervals; the data for 80 and $90 \mathrm{~m}$ were merged due to small sample sizes. Significant differences among characters between depths were checked by KruskalWallis tests followed by a post hoc Nemenyi multiple comparison (after Dunn 1964). 
Additionally, Pearson's $r$ was calculated for the four growth-invariant and growthindependent characters and proloculus size (Eder et al. 2017a) along the depth gradient. Finally, a partial correlation omitting water depth as control variable was calculated to check for correlation between the calculated characters and proloculus size.

\section{Results}

Sample size $n_{j}$, mean $x_{j}$, standard error $s e_{j}$, and the ranges are given for the characters MRmax, MaxMlTh, ThMR3, and F for every water depth $j$ (Table 1 ). The constants $b_{0} b_{1} b_{2}$, and $b_{3}$ for equation (1) and $a, b$, and $c$ for equation (2) are given in Appendix 2 in the Supplementary Material. Correlations (Pearson's $r$ and partial correlation) between the four growth-independent characters, the proloculus size, and water depth are given in Table 2 . The ratio $F$ has the strongest correlation with water depth, followed by ThMR3 and MaxMlTh, while MRmax shows the weakest, still highly significant correlation. After water depth has been partialized, the four characters correlate with each other, while proloculus size shows no significant correlation with any of the growthindependent characters characterizing test flattening (Table 2).

Differences between depths proven for MaxMlTh, ThMR3, and F by the KruskalWallis test are significant, while those for $M R \max$ are not (reported in Appendix 1 in the Supplementary Material). Results of the post hoc Nemenyi tests are presented in Table 3. The radius at the maximal mediolateral thickness MRmax shows no apparent trend, while a more or less consecutive depth trend is evident for the maximal mediolateral thickness MaxMlTh. Interestingly, a distinct excursion to thicker values occurs from 30 to $40 \mathrm{~m}$. For the thickness at $M R=3 \mathrm{~mm}$ (ThMR3), thickness decreases constantly. Based on multiple comparisons, ThMR3 can be differentiated into 5-20, 3-40, 50-60, 70, and >80 m intervals. For the flattening ratio $F$, intervals of 5-30, 40, 50, and $60-80 \mathrm{~m}$ are recognizable.

Finally, Table 4 provides the statistics showing the linear relationship between MRmax and MaxMlTh. The slope $k$ of the regression line steadily decreases toward deeper samples, except a short excursion at $10 \mathrm{~m}$, whereas $p$-values and coefficients of variation remain similar between

TABLE 1. Summary table for the morphometric characters: sample size $n$, mean $\bar{x}_{j}$, SE, minimum (Min.) and maximum (Max.) for the characters MRmax, MaxMlTh, and ThMR3, and $F$ for every water depth $j$.

\begin{tabular}{|c|c|c|c|c|c|c|c|c|c|}
\hline \multirow[b]{2}{*}{ Depth (m) } & \multirow[b]{2}{*}{$n$} & \multicolumn{4}{|c|}{$M R \max$} & \multicolumn{4}{|c|}{ MaxMlTh } \\
\hline & & $\bar{x}$ & SE & Min. & Max. & $\bar{x}$ & SE & Min. & Max. \\
\hline 5 & 13 & 725.0 & 26.55 & 636.1 & 617.4 & 473.6 & 22.91 & 328.4 & 617.4 \\
\hline 10 & 15 & 766.1 & 28.65 & 590.2 & 562.0 & 467.5 & 13.60 & 368.3 & 562.0 \\
\hline 20 & 15 & 724.7 & 31.91 & 553.1 & 565.7 & 453.7 & 15.67 & 360.3 & 565.7 \\
\hline 30 & 15 & 673.0 & 41.30 & 415.0 & 679.5 & 423.1 & 30.04 & 292.4 & 679.5 \\
\hline 40 & 15 & 802.6 & 38.85 & 570.5 & 699.6 & 471.4 & 25.12 & 306.6 & 699.6 \\
\hline 50 & 15 & 847.9 & 70.97 & 504.3 & 747.7 & 450.3 & 38.56 & 264.2 & 747.7 \\
\hline 60 & 15 & 884.8 & 55.76 & 664.6 & 549.6 & 419.5 & 25.32 & 274.7 & 549.6 \\
\hline 70 & 15 & 841.2 & 82.36 & 373.3 & 639.2 & 388.9 & 38.01 & 198.2 & 639.2 \\
\hline \multirow[t]{2}{*}{80} & 9 & 819.7 & 133.63 & 348.9 & 433.3 & 332.6 & 29.87 & 199.6 & 433.3 \\
\hline & & \multicolumn{4}{|c|}{ ThMR3 } & \multicolumn{4}{|c|}{$F$} \\
\hline Depth (m) & $n$ & $\bar{x}$ & SE & Min. & Max. & $\bar{x}$ & SE & Min. & Max. \\
\hline 5 & 13 & 1038.3 & 59.24 & 772.4 & 1501.3 & 0.7 & 0.02 & 0.5 & 0.8 \\
\hline 10 & 15 & 1028.6 & 49.04 & 813.8 & 1518.0 & 0.6 & 0.02 & 0.5 & 0.7 \\
\hline 20 & 15 & 1041.3 & 41.32 & 788.2 & 1364.3 & 0.6 & 0.02 & 0.5 & 0.8 \\
\hline 30 & 15 & 973.8 & 57.98 & 638.0 & 1434.0 & 0.6 & 0.03 & 0.4 & 0.8 \\
\hline 40 & 15 & 941.7 & 42.96 & 698.5 & 1234.8 & 0.6 & 0.02 & 0.5 & 0.7 \\
\hline 50 & 15 & 889.9 & 44.58 & 686.2 & 1178.5 & 0.5 & 0.02 & 0.4 & 0.7 \\
\hline 60 & 15 & 856.2 & 52.15 & 588.9 & 1244.0 & 0.5 & 0.03 & 0.3 & 0.7 \\
\hline 70 & 15 & 789.8 & 54.00 & 465.3 & 1207.7 & 0.5 & 0.02 & 0.3 & 0.6 \\
\hline 80 & 9 & 677.8 & 44.37 & 433.8 & 867.5 & 0.4 & 0.04 & 0.3 & 0.6 \\
\hline
\end{tabular}


TABLE 2. Correlation tables for water depth, growth-invariant characters, and proloculus size $P$. Note the nonsignificant correlation between the characters and proloculus size after water depth was partialized. Degrees of freedom $=127$ for all Pearson's $r$ values; degrees of freedom $=124$ for all partial correlation values. Corr., correlation coefficient. Underlining indicate $p<0.05$.

\begin{tabular}{|c|c|c|c|c|c|c|}
\hline \multicolumn{7}{|c|}{ Pearson's $r$} \\
\hline & & $M R \max$ & MaxMlTh & ThMR3 & $F$ & $P$ \\
\hline Depth (m) & Corr. & $\begin{array}{l}0.225 \\
0.006\end{array}$ & $\begin{array}{l}-0.29 \\
4.67 \mathrm{~F}-04\end{array}$ & $\begin{array}{l}-0.491 \\
223 \mathrm{E}-09\end{array}$ & $\begin{array}{l}-0.599 \\
638 \mathrm{~F}-14\end{array}$ & $\begin{array}{l}0.747 \\
340 \text { - } 24\end{array}$ \\
\hline$M R \max$ & Corr. & & $\begin{array}{l}0.623 \\
2.56 \mathrm{E}-15\end{array}$ & $\begin{array}{l}0.219 \\
0.007\end{array}$ & $\begin{array}{r}-0.384 \\
4.49 \mathrm{E}-06\end{array}$ & $\begin{array}{l}0.203 \\
0.011\end{array}$ \\
\hline MaxMlTh & Corr. & & & $\begin{array}{l}\overline{0.689} \\
1.61 \mathrm{E}-19\end{array}$ & $\begin{array}{l}0.418 \\
5.53 \mathrm{E}-07\end{array}$ & $\begin{array}{r}-0.237 \\
0.004\end{array}$ \\
\hline ThMR3 & $\begin{array}{l}\text { Corr. } \\
p\end{array}$ & & & & $\begin{array}{l}0.537 \\
4.56 \mathrm{E}-11\end{array}$ & $\begin{array}{l}-\overline{0.442} \\
1.02 \mathrm{E}-07\end{array}$ \\
\hline$F$ & $\begin{array}{l}\text { Corr. } \\
p\end{array}$ & & & & & $\begin{array}{r}-\overline{0.473} \\
1.11 \mathrm{E}-08 \\
\end{array}$ \\
\hline \multicolumn{7}{|c|}{ Partial correlation } \\
\hline Control va & depth & MaxMlTh & ThMR3 & $F$ & $P$ & \\
\hline Mrmax & Corr. & $\begin{array}{l}0.761 \\
4.02 \mathrm{E}-25\end{array}$ & $\begin{array}{l}0.406 \\
1.35 \mathrm{E}-06\end{array}$ & $\begin{array}{l}-0.345 \\
3.98 \mathrm{E}-05\end{array}$ & $\begin{array}{r}-0.009 \\
0.462\end{array}$ & \\
\hline MaxMlTh & Corr. & & $\begin{array}{l}0.657 \\
4.70 \mathrm{E}-17\end{array}$ & $\begin{array}{l}0.317 \\
1.61 \mathrm{E}-04\end{array}$ & $\begin{array}{r}-0.042 \\
0.320\end{array}$ & \\
\hline$T h M R 3$ & $\begin{array}{l}\text { Corr. } \\
p\end{array}$ & & & $\begin{array}{l}\overline{0.350} \\
3.10 \mathrm{E}-05\end{array}$ & $\begin{array}{r}-0.132 \\
0.071\end{array}$ & \\
\hline$F$ & Corr. & & & & $\begin{array}{r}-0.055 \\
0.272\end{array}$ & \\
\hline
\end{tabular}

TABLE 3. The results of the nonparametric multiple comparison as triangular matrices. The upper triangle gives the significance (underlined: $q<q(0.05,8)$ ), and the lower triangle shows the acceptance of $H_{0}$ (sample median is the same).

Rejection of $H_{0}$ is indicated in bold. Numbers above columns are the water-depth intervals in meters. See text for a discussion of Nemenyi tests.

\begin{tabular}{|c|c|c|c|c|c|c|c|c|c|}
\hline \multicolumn{10}{|c|}{ Nemenyi (after Dunn 1964) } \\
\hline MaxMlTh & 5 & 10 & 20 & 30 & 40 & 50 & 60 & 70 & 80 \\
\hline 5 & & 0.089 & 2.121 & 6.775 & 0.613 & 4.218 & 6.054 & 8.545 & 11.647 \\
\hline 10 & accept & & 2.188 & 7.200 & 0.565 & 4.447 & 6.424 & 9.106 & 12.247 \\
\hline 20 & $\frac{r}{\text { accept }}$ & accept & & 5.012 & 1.624 & 2.259 & 4.235 & 6.918 & 10.606 \\
\hline 30 & reject & reject & reject & & 6.635 & 2.753 & 0.776 & 1.906 & 6.847 \\
\hline 40 & accept & accept & accept & reject & & 3.882 & 5.859 & 8.541 & 11.824 \\
\hline 50 & $\frac{1}{\text { reject }}$ & $\overline{\text { reject }}$ & $\frac{1}{\text { accept }}$ & accept & reject & & 1.976 & 4.659 & 8.912 \\
\hline 60 & reject & reject & reject & $\frac{\mathrm{r}}{\mathrm{accept}}$ & reject & accept & & 2.682 & 7.429 \\
\hline 70 & reject & reject & reject & $\frac{r}{\text { accept }}$ & reject & reject & accept & & 5.418 \\
\hline 80 & reject & reject & reject & reject & reject & reject & reject & reject & \\
\hline ThMR3 & 5 & 10 & 20 & 30 & 40 & 50 & 60 & 70 & 80 \\
\hline 5 & & 0.114 & 1.568 & 3.697 & 4.506 & 7.477 & 9.771 & 13.071 & 15.031 \\
\hline 10 & accept & & 1.812 & 3.859 & 4.729 & 7.929 & 10.400 & 13.953 & 15.806 \\
\hline 20 & $\frac{1}{\text { accept }}$ & accept & & 5.671 & 6.541 & 9.741 & 12.212 & 15.765 & 17.165 \\
\hline 30 & $\frac{1}{\text { reject }}$ & $\overline{\text { reject }}$ & reject & & 0.871 & 4.071 & 6.541 & 10.094 & 12.912 \\
\hline 40 & reject & reject & reject & accept & & 3.200 & 5.671 & 9.224 & 12.259 \\
\hline 50 & reject & reject & reject & reject & reject & & 2.471 & 6.024 & 9.859 \\
\hline 60 & reject & reject & reject & reject & reject & accept & & 3.553 & 8.006 \\
\hline 70 & reject & reject & reject & reject & reject & reject & reject & & 5.341 \\
\hline 80 & reject & reject & reject & reject & reject & reject & reject & reject & \\
\hline$F$ & 5 & 10 & 20 & 30 & 40 & 50 & 60 & 70 & 80 \\
\hline 5 & & 3.884 & 1.808 & 2.180 & 7.205 & 14.044 & 17.299 & 19.724 & 16.058 \\
\hline 10 & reject & & 2.235 & 1.835 & 3.576 & 10.941 & 14.447 & 17.059 & 13.847 \\
\hline 20 & accept & accept & & $\overline{0.400}$ & 5.812 & 13.176 & 13.176 & 19.294 & 15.524 \\
\hline 30 & $\frac{1}{\text { accept }}$ & $\frac{1}{\text { accept }}$ & reject & & 5.412 & 12.776 & 16.282 & 18.894 & 15.224 \\
\hline 40 & $\frac{r}{\text { reject }}$ & reject & reject & reject & & 7.365 & 10.871 & 13.482 & 11.165 \\
\hline 50 & reject & reject & reject & reject & reject & & 3.506 & 6.118 & 5.641 \\
\hline 60 & reject & reject & reject & reject & reject & reject & & 2.612 & 1.053 \\
\hline 70 & reject & reject & reject & reject & reject & reject & accept & & 1.053 \\
\hline 80 & reject & reject & reject & reject & reject & reject & $\frac{1}{\text { accept }}$ & accept & \\
\hline
\end{tabular}


TABLE 4. Linear regression between MRmax and MaxMlTh at water-depth interval $j$. Slope $k$ of the regression line, the correlation coefficient $R$, and its probability $p$ for the linear regression are given. $R$ is the Pearson's correlation coefficient for the goodness of fit between the observed and estimated values.

\begin{tabular}{lccl}
\hline \hline Depth $(\mathrm{m})$ & $k$ & $R$ & $p$ \\
\hline 5 & 0.646 & 0.646 & 0.009 \\
10 & 0.604 & 0.587 & 0.022 \\
20 & 0.618 & 0.723 & 0.002 \\
30 & 0.625 & 0.752 & 0.001 \\
40 & 0.585 & 0.766 & 0.009 \\
50 & 0.525 & 0.923 & $9.41 \mathrm{E}-07$ \\
60 & 0.455 & 0.715 & 0.003 \\
70 & 0.454 & 0.841 & $8.63 \mathrm{E}-05$ \\
80 & 0.369 & 0.865 & 0.003 \\
\hline
\end{tabular}

samples. Regression lines illustrate the linear relationship between MRmax and MaxMlTH for every water-depth interval $j$ (Fig. 5).

\section{Discussion}

The methodology presented here solves a problem in quantifying thickening and flattening tendencies in larger benthic foraminiferal tests in relation to water depth. The ontogenetic development of test thickness in $H$. depressa can be approximated by a power function correlating test thickness to the marginal radius (or diameter), and its value thus

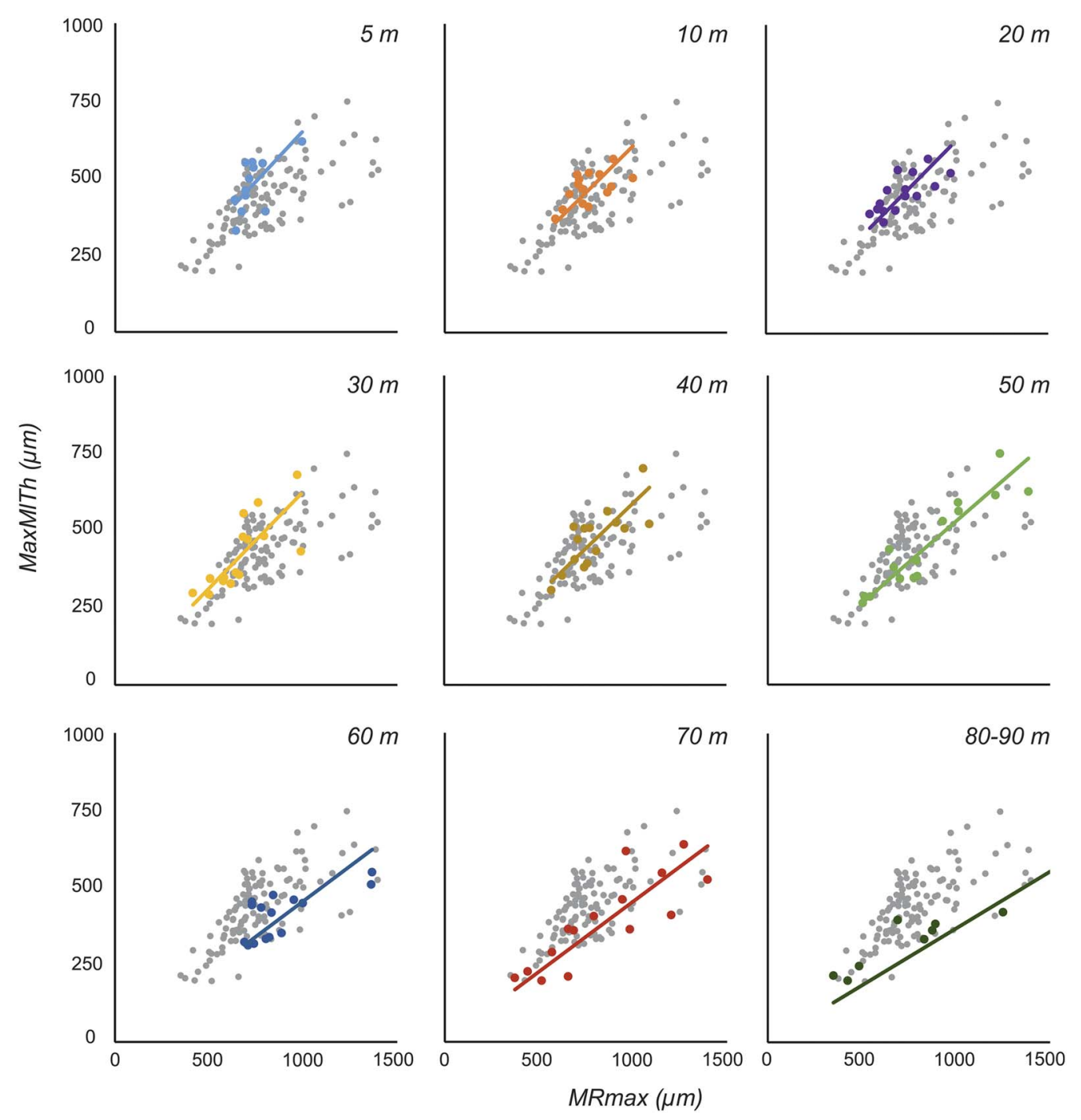

FIGURE 5. Regression lines between MRmax and MaxMlTh following $y=k x$ (running through the origin), manifesting the correct use of the flattening ratio $F$ for every investigated water depth. 

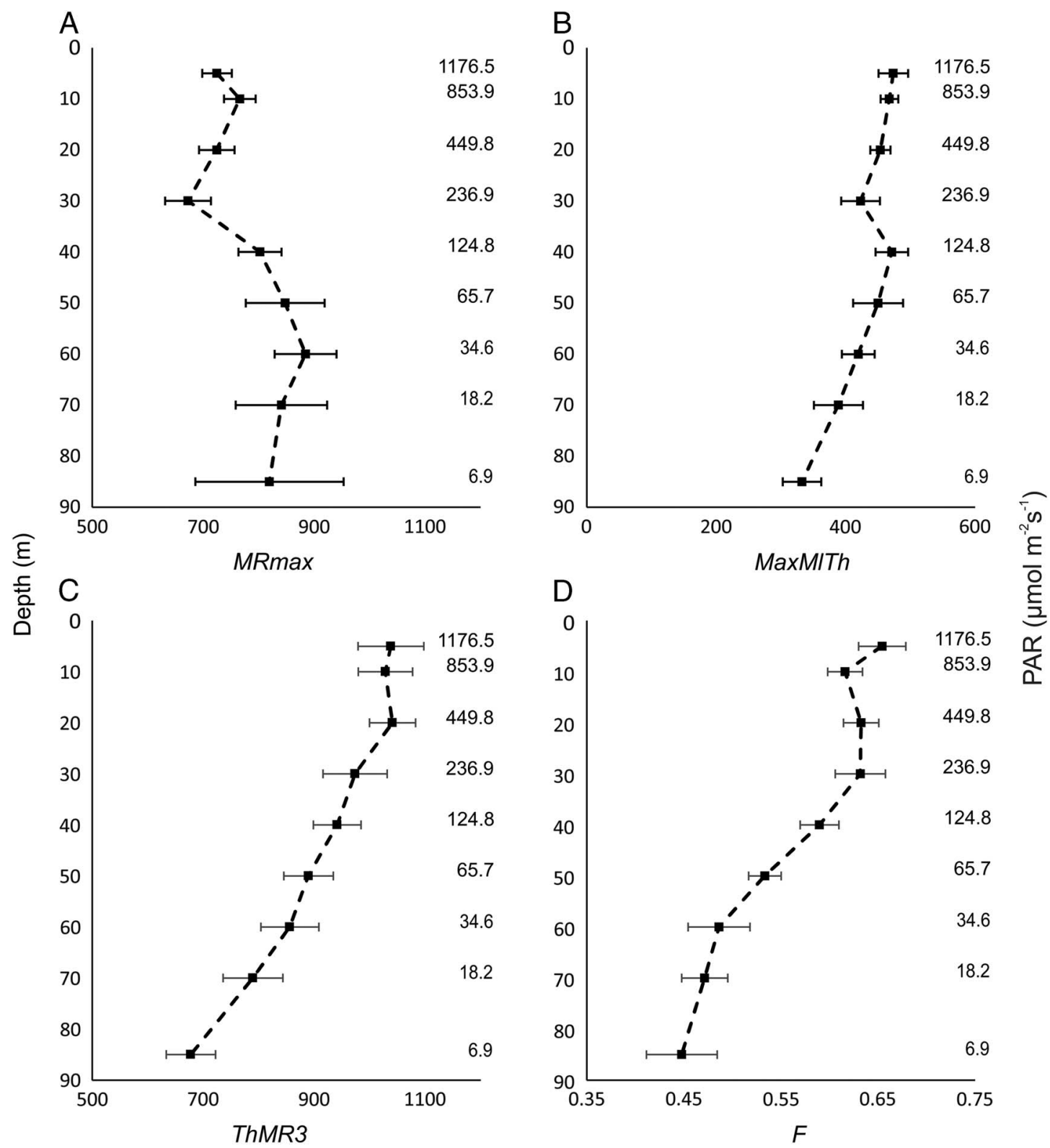

FIGURE 6. The mean and standard error of the growth-invariant characters plotted against water depth (left ordinate) and light intensity (right ordinate). A, Marginal radius at the maximal mediolateral thickness (MRmax); $\mathrm{B}$, maximal mediolateral thickness (MaxMlTh); $\mathrm{C}$, thickness at $M R=3000 \mu \mathrm{m}(T h M R 3) ; \mathrm{D}$, flattening ratio $F$.

changes with increasing test diameter. The commonly used $T / D$ ratio does not vary in isometrically growing tests (e.g., Amphisteginids) and can still be of some use, but it is highly growth dependent in all allometrically growing tests (e.g., H. depressa), and its use as a depth indicator is strongly discouraged.

Based on this function, thickness was computed for every specimen at a marginal radius of
$3 \mathrm{~mm}(3000 \mu \mathrm{m})$, which bypasses the problem of growth dependence by comparing specimens using this fixed radius. The thickness ThMR3 gives accurate results on water depth, showing a clear depth trend (Fig. 6C). Thickness, however, provides no direct information on the degree of flattening, which is especially interesting for the so-called maturo-evolute shape of $H$. depressa (Banner and Hodgkinson 1991) and for 
other nummulitids showing similar flattening tendencies. Tests with thickened centers and thinner peripheries occur in several fossil (e.g., Spiroclypeus, Heterostegina) and extant nummulitid genera (e.g., Palaeonummulites, Operculinella, Cycloclypeus). To describe and quantify such geometry, we have introduced the maximal mediolateral thickness (MaxMlTh; Fig. 6B), the corresponding marginal radius (MRmax; Fig. 6A), and the flattening ratio (F; Fig. 6D) (Fig. 4). The maximal mediolateral thickness (MaxMlTh) remains more or less constant at water depths from 5 to $30 \mathrm{~m}$, while the trend shows a sudden excursion to thicker values at $40 \mathrm{~m}$ and then decreases consistently for deeper samples (Fig. $6 \mathrm{~B})$. This distinctive setback in the trend seems to record the change from reef-associated to sandy habitats, since specimens become thicker on sandy bottoms to resist entrainment by orbital wave movement (Briguglio and Hohenegger 2011). This habitat-related change is also reflected in the flattening ratio $F$ (Fig. 6D). The similar ratios from 5 to $30 \mathrm{~m}$ correlate with reefassociated habitats, which are built up of highly diverse structures (e.g., shaded areas, tide pools, reef crevices). Samples from 40 and $50 \mathrm{~m}$ correspond to the transition zone between reefassociated habitats and sandy bottoms. This zone is characterized by an intercalation of reef debris and few living corals (Hohenegger 2004). The deepest samples $(60$ to $>80 \mathrm{~m}$ ) correlate with sandy bottoms in a low-energy setting.

The reason for a decrease in thickness has been thoroughly discussed, and it is widely accepted that hydrodynamic energy and light intensity have a synergetic influence on test thickness (Larsen and Drooger 1977; Hallock 1979; Hohenegger 2004). Nonetheless, our results on test flattening show that specimens from different depths are influenced by these factors in different ways. A clear shift in test flattening is evident from the high-energy, reef-associated samples to the transitional zone and to deeper, low-energy samples (Fig. 7). This implies that, in shallower environments, mechanical strengthening of the test is more important, whereas in deeper slope environments, light intensity is the major factor controlling test shape. The differences in internal morphology of the two bathymetrically separated megalospheric generations (gamonts and schizonts), as reported in Eder et al. (2017a), are not reflected in test thickness and flattening (Table 2, partial correlation).

Furthermore, the rather stable values of the characters ThM3 and F (Fig. 5C,D) in shallower samples proposes a realized maximal limit of total test thickness around the efficiency optimum of the host's symbionts. This limitation in morphological plasticity seems to be around $30 \mathrm{~m}$ water depth, coinciding with the maximal abundance of $H$. depressa in oligotrophic environments (Hohenegger 2000). Structured reefassociated habitats may allow Heterostegina to settle in even shallower water depths, because they can populate shaded areas and holes to counteract high light intensities and entrainment (Hohenegger 2004).

While hydrodynamics and light intensity are the general factors controlling thickness, other factors such as water transparency, sedimentary composition, and habitat structure also affect test shape. Further, one should comment that light attenuation might alter light intensity drastically based on grain size and turbidity. In other localities, stronger turbidity or higher terrestrial input might reduce light intensity and distort the depth morphoclines established in the present study (Hohenegger 2004). However, within the carbonate environments of Sesoko-Jima the light attenuation factor is around 0.06 (Hohenegger et al. 1999), which is in accordance with the general values around $0.056( \pm 0.009)$ published by Hallock (1987). Therefore, the data presented here can be used to establish a model for oligotrophic rimmed-shelf environments. Accordingly, large-scale (meters) structured habitats (e.g., reefs and reef debris) diminish the influence of light intensity and hydrodynamic energy on the test of $H$. depressa, whereas in lowscale (centimeters) structured habitats (e.g., sandy to silty bottoms) the exposure to physical influences is stronger (Fig. 7). Conversely, the sediment distribution along the slope is primarily influenced by hydrodynamic energy and submarine topography, creating complex synergetic effects.

This calls for taking the absence/presence of reef environments and slope topography (e.g., steep drop-offs) into account when considering test thickness and flattening as depth indicators. Especially for paleontological applications, different paleoenvironmental indicators must 

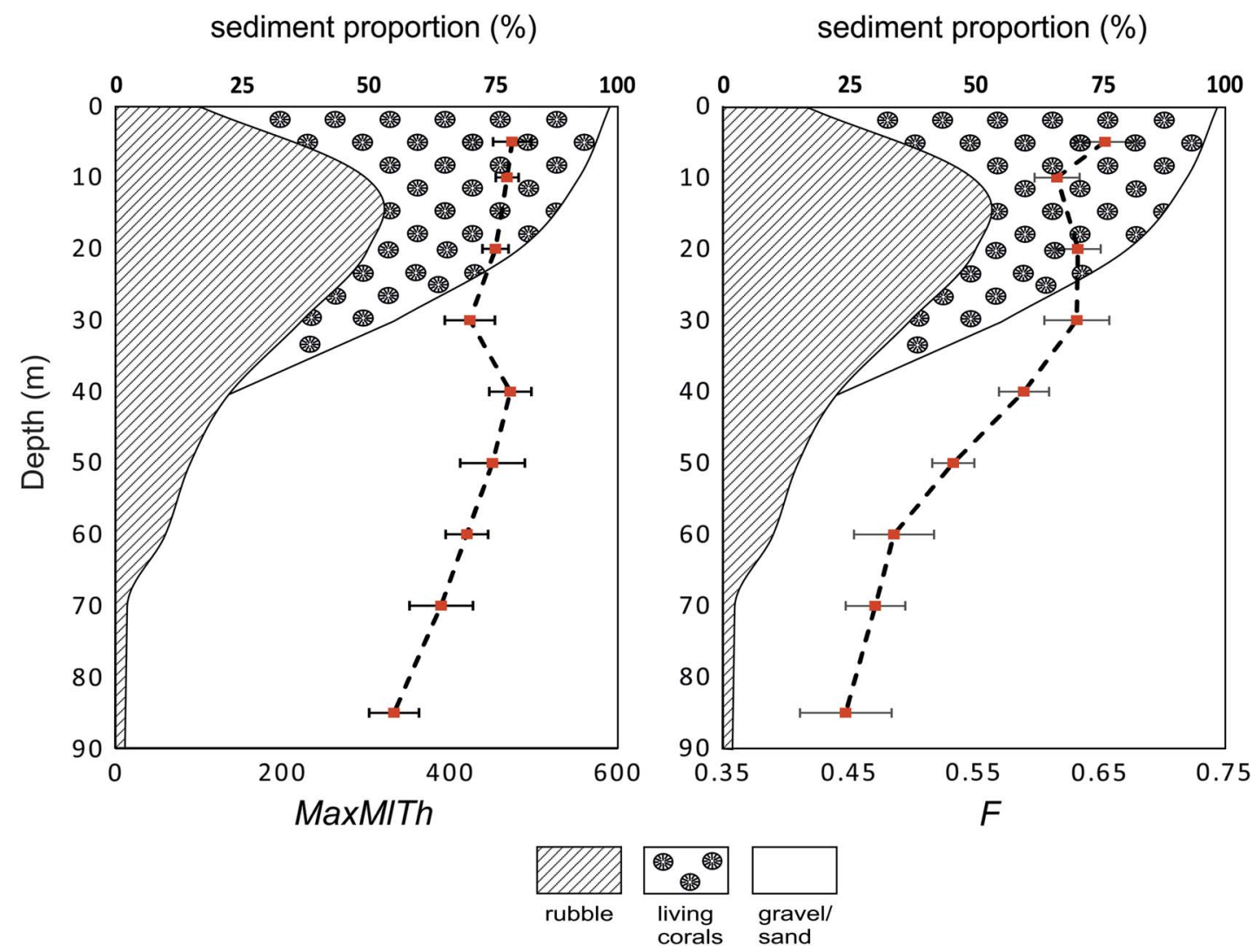

FIGURE 7. Maximal mediolateral thickness and flattening ratio are plotted against sediment proportion of the corresponding transects (Hohenegger 2004). Note the relatively constant values in the reef-dominated environments.

be integrated to cross-correlate with the information obtained from test thickness and test flattening in nummulitids. Ramp-like slope morphologies, typical of Paleogene shallowmarine environments, which lack major bioherms, might be a key factor in the emergence of secondary growth in thickness as an adaptation to highly illuminated, high-energy environments. In the diverse heterostegenid taxa, a strict differentiation of lateral chambers must be made between lateral chamberlets (e.g., Heterostegina sensu lato, Tansinhokella, and Grzybowskia) and orbitoid-type "cubicula" (e.g., Spiroclypeus) (Banner and Hodgkinson 1991). Only in the first case, where spiral and lateral growth steps take place simultaneously, can the present methodology be applied.

To estimate the degree of mixture in fossil assemblages the means, standard errors, variances, and coefficients of variation of $H$. depressa subpopulations from different water depths can be used as indicator values. Populations from autochthonous deposits should exhibit similar mean, standard errors, and coefficients of variation in the computed characters, while allochthonous populations should show significantly wider standard error limits, variances, and coefficients of variation. For the further application of this methodology to fossil communities, an integration with microfacies analysis is essential, since this constrains the hydrodynamic regime, which is one of the major factors influencing test flattening. In serial thin sections, oriented axial sections are quite frequent, hence the approaches presented here can be combined to tackle the question of the hydrodynamic regime and degree of transport.

\section{Conclusions}

The ontogenetic development of thickness in $H$. depressa can be described either by a power 
function for thickness or by a complex function for mediolateral thickness. These functions yield four growth-invariant characters, enabling a detailed quantification of trends in test thickness and flattening.

The character ThMR3 describes the theoretical thickness at the fixed size of $M R=3000 \mu \mathrm{m}$, while the maximal mediolateral thickness MaxMlTh describes the thickness at the onset of test flattening, which is especially important for maturo-evolute nummulitid taxa. The relation between the marginal radius MRmax and the maximal mediolateral thickness can be exemplified as the flattening ratio $F$.

Our results indicate that the thickness ThMR3 and the flattening ratio $F$ allow the best bathymetric estimation. The generally accepted factors influencing test shapes in LBF are light intensity and hydrodynamic energy, although they show complex synergetic effects with terrigenous influx and sediment composition. Shallower samples from reef-associated habitats show no distinct changes in their degree of flattening down to $30 \mathrm{~m}$ water depth. This is because extrinsic factors are partially cancelled out due to the large-scale, three-dimensional structure of the microhabitat in firm substrates providing protected areas. Thus, test thickness seems to be a habitat-independent indicator for bathymetric changes based on a combination of light intensity and hydrodynamics, with a continuous decrease in both factors. In contrast, the flattening ratio incorporates additional information on the sediment composition of the habitat. Test-flattening studies at localities with higher nutrient input and/or stronger light attenuation should be conducted carefully, since shape trends are shifted toward lower values.

We were unable to detect a connection between internal morphology in the different megalospheric generations (e.g., proloculus size) and test thickness or flattening. A similar tendency of flattening in microspheric generation remains to be tested.

Since similar ecological constraints can be assumed for recent and fossil heterostegenid taxa, the dependence on water depth expressed by different test thicknesses, as established in this study, allows reconstructing bathymetric distributions of autochthonous fossil populations. Moreover, this potentially provides clues on the degree of transport in allochthonous deposits and enables more detailed reconstructions of paleoenvironments of fossil larger benthic foraminiferal communities. Importantly, in those taxa exhibiting a secondary growth in thickness, a strict differentiation must be made between lateral chamberlets and cubicula.

\section{Acknowledgments}

This work was performed at the micro-CT Facility, which is part of the Department of Palaeontology at the University of Vienna, Austria. This study was done within the project "Breakthroughs in Growth Studies on Larger Benthic Foraminifera" of the Austrian Science Fund (FWF; grant P26344-B25). We would like to thank Michael Stachowitsch for proofreading this manuscript. Finally, we would like to extend our gratitude to the three anonymous reviewers who helped to improve the article.

\section{Literature Cited}

Banner, F. T., and R. L. Hodgkinson. 1991. A revision of the foraminiferal subfamily Heterostegininae. Revista Espanola de Micropaleontologia 23:101-140.

Beavington-Penney, S. J., and A. Racey. 2004. Ecology of extant nummulitids and other larger benthic foraminifera: applications in palaeoenvironmental analysis. Earth-Science Reviews 67: 219-265.

BouDagher-Fadel, M. K. 2008. Evolution and geological significance of larger benthic foraminifera. Elsevier, Amsterdam.

Briguglio, A., and J. Hohenegger. 2009. Nummulitid hydrodynamics: an example using Nummulites globulus Leymerie. Bollettino della societa paleontologica italiana 48:105-111.

- 2011. How to react to shallow water hydrodynamics: the larger benthic foraminifera solution. Marine Micropaleontology 81(1-2):63-76.

Briguglio, A., J. Hohenegger, and G. Less. 2013. Paleobiological applications of three-dimensional biometry on larger benthic foraminifera: a new route of discoveries. Turkish Journal of Earth Sciences 43:72-87.

Cahuzac, B., and A. Poignant. 1997. Essai de biozonation de l'Oligo-Miocène dans les bassins européens à l'aide des grands foraminifères néritiques. Bulletin de la Société géologique de France 168:155-169.

Cosovic, V., K. Drobne, and A. Moro. 2004. Paleoenvironmental model for Eocene foraminiferal limestones of the Adriatic carbonate platform (Istrian Peninsula). Facies 50:61-75.

d'Orbigny, A. D. 1826. Tableau méthodique de la classe des Céphalopodes. Annales des Sciences Naturelles, série, 7:305.

Dunn, O. J. 1964. Multiple comparisons using rank sums. Technometrics 6:241-252.

Eder, W., A. Briguglio, and J. Hohenegger. 2016. Growth of Heterostegina depressa under natural and laboratory conditions. Marine Micropaleontology 122:27-43. 
Eder, W., J. Hohenegger, and A. Briguglio. 2017a. Depth-related morphoclines of megalospheric test of Heterostegina depressa d'Orbigny: biostratigraphic and palaeobiological implications. Palaios 32:110-117.

Eder, W., J. Hohenegger, A. I. Torres-Silva, and A. Briguglio. 2017b. Morphometry of the larger foraminifera Heterostegina explaining environmental dependence, evolution and paleogeographic diversification. Pp 195-206 in P. Hallock, M. Prazeres, R. Willem, and C. F. Barbosa, eds. Proceedings of the 13th International Coral Reefs Symposium. Honolulu, Hawaii. http:/ / coralreefs. org/conferences-and-workshops/proceedings-of-icrs13-2016.

Ferrandez-Canadell, C., A. Briguglio, J. Hohenegger, and J. Woger. 2014. Test fusion in adult foraminifera: a review with new observations of an Early Eocene Nummulites specimen. Journal of Foraminiferal Research 44:316-324.

Hallock, P. 1979. Trends in test shape with depth in large symbiontbearing foraminifera. Journal of Foraminiferal Research 9: 61-69.

- 1987. Fluctuations in the trophic resource continuum: a factor in global diversity cycles? Paleoceanography 2:457-471.

- 1988. The role of nutrient availability in bioerosion: consequences to carbonate buildups. Palaeogeography, Palaeoclimatology, Palaeoecology 63:275-291.

— . 2000. Symbiont-bearing foraminifera: harbingers of global change? Micropaleontology 46(Suppl. 1):95-104.

Hallock, P., and E. C. Glenn. 1986. Larger foraminifera: a tool for paleoenvironmental analysis of Cenozoic carbonate depositional facies. Palaios 1:55-64.

Hallock, P., L. B. Forward, and H. J. Hansen. 1986. Influence of environment on the test shape of Amphistegina. Journal of Foraminiferal Research 16:224-231.

Hallock, P., R. Röttger, and K. Wetmore. 1991. Hypotheses on form and function in foraminifera. Pp 41-72 in J. J. Lee, and O. R. Anderson, eds. Biology of Foraminifera. Academic, New York.

Haynes, J. 1965. Symbiosis, wall structure and habitat in foraminifera. Contributions from the Cushman Foundation for Foraminiferal Research 16(1):40-43.

Hohenegger, J. 2000. Coenoclines of larger foraminifera. Micropaleontology 46:127-151.

- 2004. Depth coenoclines and environmental considerations of western Pacific larger foraminifera. Journal of Foraminiferal Research 34:9-33.

—. 2009. Functional shell geometry of symbiont-bearing benthic foraminifera. Galaxea, Journal of Coral Reef Studies 11(2):81-89.

—. 2011a. Growth-invariant meristic characters. Tools to reveal phylogenetic relationships in Nummulitidae (Foraminifera). Turkish Journal of Earth Sciences 20:655-681.

—. 2011b. Larger foraminifera: greenhouse constructions and gardeners in the oceanic microcosm. Kagoshima University Museum, Kagoshima, Japan.
Hohenegger, J., and A. Briguglio. 2012. Axially oriented sections of nummulitids: a tool to interpret larger benthic foraminiferal deposits. Journal of Foraminiferal Research 42:134-142.

Hohenegger, J., E. Yordanova, Y. Nakano, and F. Tatzreiter. 1999. Habitats of larger foraminifera on the upper reef slope of Sesoko Island, Okinawa, Japan. Marine Micropaleontology 36:109-168.

Holzmann, M., J. Hohenegger, and J. Pawlowski. 2003. Molecular data reveal parallel evolution in nummulitid foraminifera. Journal of Foraminiferal Research 33:277-284.

Holzmann, M., C. Berney, and J. Hohenegger. 2006. Molecular identification of diatom endosymbionts in nummulitid foraminifera. Symbiosis 42:93-101.

Hottinger, L. 1977a. Distribution of larger Peneroplidae, Borelis and Nummulitidae in the Gulf of Elat, Red Sea. Utrecht Micropaleontological Bulletins 15:35-109.

1977b. Foraminifères operculiniformes. Éditions du Muséum, Paris.

- 2000. Functional morphology of benthic foraminiferal shells, envelopes of cells beyond measure. Micropaleontology 46:57-86.

Larsen, A., and C. Drooger. 1977. Relative thickness of the test in the Amphistegina species of the Gulf of Elat. Utrecht Micropaleontological Bulletin 15:225-239.

Nobes, K., S. Uthicke, and R. Henderson. 2008. Is light the limiting factor for the distribution of benthic symbiont bearing foraminifera on the Great Barrier Reef? Journal of Experimental Marine Biology and Ecology 363(1-2):48-57.

Prazeres, M., S. Uthicke, and J. M. Pandolfi. 2015. Ocean acidification induces biochemical and morphological changes in the calcification process of large benthic foraminifera. Proceedings of the Royal Society of London B 282:20142782.

Reiss, Z., and L. Hottinger. 1984. The Gulf of Aqaba: ecological micropaleontology. Springer-Verlag, Berlin.

Renema, W. 2005. Depth estimation using diameter-thickness ratios in larger benthic foraminifera. Lethaia 38:137-141.

Seddighi, M., A. Briguglio, J. Hohenegger, and C. A. Papazzoni. 2015. New results on the hydrodynamic behaviour of fossil Nummulites tests from two nummulite banks from the Bartonian and Priabonian of northern Italy. Bollettino della societa paleontologica italiana 54:103-116.

Serra-Kiel, J., L. Hottinger, E. Caus, K. Drobne, C. Ferrandez, A. K. Jauhri, G. Less, R. Pavlovec, J. Pignatti, and J. M. Samso. 1998. Larger foraminiferal biostratigraphy of the Tethyan Paleocene and Eocene. Bulletin de la Société géologique de France 169: 281-299.

Speijer, R. P., D. Van Loo, B. Masschaele, J. Vlassenbroeck, V. Cnudde, and P. Jacobs. 2008. Quantifying foraminiferal growth with high-resolution X-ray computed tomography: new opportunities in foraminiferal ontogeny, phylogeny, and paleoceanographic applications. Geosphere 4:760-763. 